\title{
CELSO FURTADO, POLÍTICA E PLANEJAMENTO ECONÔMICO: REVISITANDO A LUTA PARA A SUPERAÇÃO DO SUBDESENVOLVIMENTO DO NORDESTE
}

\author{
Victor Emmanuel Feitosa Hortencio \\ Doutorando do Programa de Pós-Graduação em Economia da Universidade Federal da Bahia \\ (PPGE-UFBA), Bahia, BA, Brasil. \\ victor.vefh@gmail.com
}

Ana Maria Rita Milani

Doutora do Programa de Pós-graduação em Economia da Universidade Federal do Rio Grande do Sul (2010), professora adjunta da Universidade Federal de Alagoas, Maceió, AL, Brasil. anamilani16@hotmail.com

\begin{abstract}
Resumo - O presente trabalho procura fazer uma reflexão teórica do pensamento de Celso Furtado, usando sua obra como referência para entender a problemática da questão regional nordestina. $\mathrm{O}$ estudo envolve fundamentalmente a pesquisa bibliográfica em obras essenciais do autor, como também, a coleta de dados socioeconômicos. Descreve a formação econômica do Nordeste e a tentativa de Furtado em transformar a realidade subdesenvolvida da região, aliando planejamento econômico com políticas públicas através da SUDENE.Tendo como objetivo geral elucidar a problemática do Nordeste subdesenvolvido através de três objetivos específicos: 1) o sentido de desenvolvimento e subdesenvolvimento na obra de Celso Furtado; 2) derivar da abordagem mais geral, por meio do método estruturalista, a questão do atraso nordestino; e 3) descrever a tentativa de Furtado de transformar a realidade subdesenvolvida do Nordeste.
\end{abstract}

Palavras-chave: Desenvolvimento;Subdesenvolvimento;Questão Regional; Nordeste.

\section{CELSO FURTADO, POLICY AND ECONOMIC PLANNING: REVISITING THE FIGHT FOR THE DEVELOPMENT OF THE NORTHEAST SUBDESENVOLVEMENT}

\begin{abstract}
This paper seeks to make a theoretical reflection of the thought of Celso Furtado, using his work as a reference for understanding the problems of Northeastern regional issue. The study involves primarily the bibliographical research in essential works of the author, as well as socioeconomic data collection. Describes the economic formation of Northeast and attempting to Furtado in transforming the reality of the underdeveloped region, combining economic planning with public policies through the SUDENE. Aiming to elucidate the general problem of underdeveloped Northeast through three specific objectives: 1) the sense of development and underdevelopment in the work of Celso Furtado; 2) derive from more general approach, through the structuralist method, the issue of delay of the Northeast; and 3) describe the attempt to Furtado of transforming the reality of the underdeveloped Northeast.
\end{abstract}

Keywords: Development, Underdevelopment, Regional Issues, Northeast.

\section{INTRODUÇÃO}

Discutir sobre o desenvolvimento econômico no Brasil e o seu direcionamento para a economia regional envolve explorar o legado intelectual de Celso Furtado. O autor integra um grupo de autores brasileiros cuja obra é essencial para se compreender a realidade nacional. Extrapolando o âmbito das ideias, foi atuante também na carreira pública, como por exemplo, dirigente da Superintendência para o Desenvolvimento do Nordeste (SUDENE), canalizando 
forças com o intuído de promover a ação que mudaria a realidade de uma região marginalizada pelo subdesenvolvimento.

Furtado parte do pressuposto de que o desenvolvimento tem uma nítida dimensão histórica, conectando o desenvolvimento e o subdesenvolvimento a forma como ocorreu à expansão da economia industrial, que se caracterizou como a evolução do sistema social de produção. Deste modo, analisa também as áreas que assimilaram como por enxerto as técnicas oriundas das regiões pioneiras no processo de Revolução Industrial, refuta a teoria das vantagens comparativas de David Ricardo e defende a industrialização nacional como um processo essencial para se chegar ao desenvolvimento. Explana sobre os dois fatores que ludibriam o processo de desenvolvimento, que são a modernização dos padrões de consumo e a dependência cultural e tecnológica.

O autor faz uso do mesmo método histórico-estrutural para identificar a razão e as origens das assimetrias no ritmo de crescimento econômico dentro da economia brasileira, vendo que a economia capitalista que regeu o desenvolvimento mundial também criou desigualdades dentro de um mesmo território nacional.

Para Furtado o planejamento econômico é a única forma de promover a superação do subdesenvolvimento, deste modo, o verdadeiro desenvolvimento é alcançado através da ativação e da canalização das forças sociais para a promoção da mudança. A política tem a função de transformar a força econômica em vetor de mudança na esfera social, usando o Estado como promotor de políticas que logrem a superação do subdesenvolvimento.

O objetivo do trabalho será, portanto, estudar o Nordeste brasileiro, buscando entender a questão da problemática nordestina sob a luz da teoria de desenvolvimento e de subdesenvolvimento econômico na obra de Celso Furtado.

Com base nesse pressuposto, progredimos em busca de atingir os seguintes objetivos específicos:

1. Entender o sentido de desenvolvimento e subdesenvolvimento na obra de CelsoFurtado, analisando o processo histórico da economia industrial inerente às duas situações, descrevendo seus mecanismos e implicações na economia mundial;

2. Derivar da abordagem mais geral de Furtado sobre o subdesenvolvimento, inclusive o método de análise, a questão da problemática do Nordeste brasileiro;

3. Descrever a tentativa de Furtado em transformar a realidade subdesenvolvida do Nordeste, aliando planejamento econômico com políticas públicas através da SUDENE;

O trabalho se subdivide em três partes, a primeira estuda os alicerces do subdesenvolvimento do Nordeste, a segunda descreve o planejamento furtadiano na luta contra o subdesenvolvimento nordestino. Em seguida, na última parte, é feita uma breve análise do que seria "A fantasia desfeita" e a situação do Nordeste pós-1964. 


\section{OS ALICERCES DO NORDESTE SUBDESENVOLVIDO}

Celso Furtado ao analisar as economias desenvolvidas e subdesenvolvidas, torna as duas condições resultado de um mesmo impulso histórico, afirma que o desenvolvimento cria condições desiguais na sua reprodução e que o desdobramento do crescimento se forma principalmente a partir da concentração. Dessa forma, a problemática

[D]o desenvolvimento econômico, no mundo todo, tende a criar desigualdades. É uma lei universal inerente ao processo de crescimento: a lei da concentração. E dentro de um país de dimensões continentais como o Brasil, de desenvolvimento espontâneo, entregue ao acaso, os imperativos desta lei tendem a criar problemas capazes de acarretar tropeços à própria formação da nacionalidade. (FURTADO, 1959, p. 10)

De maneira que essa mesma analogia da dinâmica do desenvolvimento global se aplica as regiões formadoras de um sistema nacional. Dentro de um país de grandes dimensões como o Brasil, não foi diferente, a economia capitalista que regeu o desenvolvimento originou condições de crescimento desigual dentro de um mesmo território nacional. Assim,

Permito-me dramatizar esta afirmação inicial porque estou convencido de que as crescentes disparidades regionais constituirão o mais grave problema do nosso País nesta segunda metade do século XX [...] (Ibid. p. 10)

Historicamente, o Brasil se formou ao longo de um processo de integração política de regiões desarticuladas, porém, conectadas por um lastro cultural comum. No século XIX, o território nacional era formado por uma constelação de pequenos sistemas econômicos isolados, ligados pelo comércio internacional e pela estrutura política existente. Eram pequenas feitorias voltadas para o comércio exterior, distribuídas em um imenso território, possuindo como centro formador econômico, duas culturas comerciais, o café na região Sudeste e o açúcar na região Nordeste.

Furtado teve a preocupação de medir a produtividade per capita do Nordeste ao longo dos séculos, e analisou que o nível mais alto de produtividade da região foi alcançado nos fins do primeiro século colonial. Nos séculos posteriores, houve um declínio acentuado devido ao surgimento dos grandes concorrentes do Brasil no mercado mundial. Após o estágio letárgico compreendido entre os anos de 1650 a 1900, o Nordeste passou a crescer novamente com a integração econômica com a região Centro-Sul ${ }^{1}$.

Aquela economia que perdera o impulso vindo do exterior, passou a apoiar-se cada vez mais no Centro-Sul, colocando ali o seu açúcar em regime de defesa de preço, uma série de produtos primários e mesmo algumas manufaturas, como os tecidos de algodão que chegou a exportar em escala para o mercado centro-sulino, ao ingressar na primeira fase de industrialização [...] Mas a economia do Nordeste não é somente

\footnotetext{
${ }^{1}$ No período IBGE ainda não adotava a regionalização brasileira em Norte, Nordeste, Sudeste, Sul e Centro-Oeste.O Centro-Sul, neste caso, refere-se à região Sudeste.
} 
um sistema de baixa produtividade. É também um sistema sujeito a crises sui generis de produção e emprego (FURTADO, 1959. p. 25).

O desenvolvimento econômico do Brasil iniciado nos fins do século XIX até meados do século $\mathrm{XX}$ integrou as ilhas econômicas que formavam as regiões brasileiras. Esse crescimento se consubstanciou pela constante expansão do mercado do café concentrado na região CentroSul. De modo que, a economia nordestina ao entrar em colapso com a desarticulação do mercado externo do açúcar, conseguiu sua sobrevivência graças ao comércio com a região Sudeste, que possui um mercado de maiores dimensões e em constante crescimento.

Esta articulação, que os estudiosos da economia brasileira, na primeira metade do século XX, apreciaram como forma de evolução tendente a integrar o país em uma só economia, trazia o germe dos problemas que hoje estamos enfrentando, pois reproduzia o mesmo esquema de divisão geográfica do trabalho que viciara todo o desenvolvimento da economia mundial, com suas metrópoles industrializadas e suas colônias produtoras de matérias primas (Ibid. p. 12).

Com isso, vemos que a partir do momento que a industrialização tomara força nos centros mais dinâmicos da economia nacional, as desigualdades também se acentuaram dentro do território brasileiro. Furtado mostra que não podem coexistir dentro de um mesmo território nacional uma economia regional de base industrial e um conjunto de economias primárias, pois o centro industrial irá sempre submeter às economias mais arcaicas a condição de dependência e subordinação. Assim,

[...] as relações econômicas entre uma economia industrial e as economias primárias tendem sempre a formas de exploração. (Ibid. p. 12).

Furtado (1959), tenta captar a essência dos problemas nordestinos para montar mais adiante um diagnóstico, com o intuito de usar essas informações como base na formação de projetos que teriam ação transformadora na região. $O$ autor procura a razão desse problema regional, se perguntado, porque a região do Nordeste ficou tão atrás em relação à antiga Região Centro-Sul do Brasil? Essas e outras indagações fomentaram uma discussão sobre a gênese do problema nordestino.

Antes de qualquer coisa, então, o problema do Nordeste se caracteriza como algo peculiar, único. Sendo assim, Furtado fez uma análise específica sobre sua formação econômica para tentar entender as condições estruturais de subdesenvolvimento da região.

Geograficamente, o Nordeste brasileiro se estende do Maranhão à Bahia ${ }^{2}$, tendo aproximadamente 54 milhões $^{3}$ de habitantes e com uma área de aproximadamente $1.558 .196 \mathrm{~km}^{2}$. De sorte que,

[...] constitui a mais extensa dentre as zonas de mais baixo desenvolvimento, ou

\footnotetext{
${ }^{2}$ O Nordeste é formado por nove estados (Maranhão, Ceará, Rio Grande do Norte, Paraíba, Pernambuco, Piauí, Alagoas, Sergipe e Bahia).

${ }^{3}$ De acordo com censo demográfico 2010 do IBGE.
} 
mais agudamente subdesenvolvidas, de todo Hemisfério Ocidental [...] (FURTADO, 1959, p. 20).

Furtado, em A Fantasia Desfeita,dizque é difícil exagerar com relação ao Nordeste do Brasil. A sociedade lá existente não é impulso nem de conquista, nem de projeto de colonização. Nesta região foi lançada uma operação transcontinental que visava criar um fluxo de exportação como o mercado Europeu em expansão. Pois,

Os critérios econômicos se sobrepõe a tudo. Poucas vezes na história humana uma formação social terá sido condicionada em sua gênese de forma tão cabal por fatores econômicos(FURTADO, 1989, p. 15).

No Nordeste se formou desde o século XVI uma economia baseada na exportação, voltada para a produção de açúcar para abastecer o mercado externo, uma combinação de capitalismo agroindustrial com escravidão, essa economia só crescia à medida que o produto se valorizava, ou pelo aumento de sua demanda, sendo assim, o que formava a força motriz de crescimento econômico nordestino era o comércio açucareiro. A economia açucareira se baseava no aproveitamento das terras úmidas litorâneas, que impulsionou de forma associada, o povoamento do interior nordestino, criando economias secundárias, como a pecuária. A pecuária fornecia ao litoral alimento através da carne bovina e força de tração animal com o boi. Ao contrário do que acontecia na economia açucareira, a pecuária não dependia de gastos monetários para a expansão da capacidade produtiva e no processo de reposição de capital. O autor completa que,

[O] povoamento se fez com uma técnica extremamente primitiva, à medida que o gado penetrou no interior. O homem seguiu a boiada. O gado, ao encontrar a floresta amazônica, do lado do Maranhão, parou; e se deteve ao encontrar as regiões mais áridas da depressão são franciscana. Formou-se, assim, esse grande bolsão que é o Nordeste, particularmente o chamado de Nordeste oriental, onde a população tem crescido sem cessar (FURTADO, 1959, p. 21).

A exploração do litoral e do interior consistia em dizimar a população local quando havia resistência, caso contrário, os nativos eram usados como escravos. Com o fracasso desse método de conseguir mão de obra, passou-se a existir um fluxo comercial de mão de obra africana escrava. O tempo de vida desses escravos não superava muito seu tempo de eficácia produtiva.

A economia de exportação litorânea estimulou o surgimento da produção de gêneros em regiões marginais que forneciam subsídios para esta, que tinha importância principal. De modo que, em épocas de declínio ou crises no setor exportador, as economias secundárias evoluíam se transformando em economias de subsistência. A população que sobrevivia deste tipo de economia continuava crescendo de forma persistente, mesmo com a diminuição ou estacionamento da produtividade. Assim, vemos que a expansão territorial da economia do Nordeste, de forma predominantemente, se baseou no declínio e na desagregação da economia açucareira. Por conseguinte, 
A terceira faixa da economia do Nordeste é esse hinterlandda pecuária que desde o início, se constitui em economia subsidiária do açúcar. Foi possível povoar de gado o Nordeste porque os engenhos absorviam grande quantidade de animais, não só para alimentação, mas também, e sobretudo, para tração. A fonte energética mais importante na economia açucareira era a força do animal que vinha do hinterland. Além disso, a produção de couros também permitiu, de certo, equilibrar essa pecuária. Contudo, era uma economia de baixíssima produtividade (Ibid, p. 23).

Furtado, em Formação Econômica do Brasil,argumenta que a expansão da economia nordestina neste período não crescia de forma qualitativa, a estagnação do comércio açucareiro fazia diminuir a produtividade do setor, ao passo que, a produtividade da pecuária declinava à medida que crescia. Pois o atrofiamento da renda monetária como resultado do mau desempenho do comércio externo, estimulava o crescimento vegetativo da economia pecuária, pouco monetária, resultando numa involução da economia nordestina. Logo,

\begin{abstract}
A redução relativa da renda monetária teria de repercutir no grau de especialização da economia e no sistema de divisão do trabalho dentro da mesma. Muitos artigos que antes se podiam comprar nos mercados do litoral- que eram importados- teriam agora de ser produzidos internamente. Essa produção, entretanto, limitava-se ao âmbito local, constituindo uma forma rudimentar de artesanato [...] Esse atrofiamento da economia monetária se acentua à medida que aumentam as distâncias do litoral, pois dado ao custo do transporte do gado, em condições de estagnação do mercado de animais, os criadores mais distantes se tornaram submarginais (FURTADO, 2007, p. 104).
\end{abstract}

Segundo Furtado, a zona litorânea úmida nordestina é formada por terras de maior qualidade, no entanto, se encontram em menor quantidade. Nessa mesma região se estabeleceu a especialização agrícola voltada para o fim da monocultura da cana-de-açúcar, situação que favoreceu o surgimento do latifúndio, inibindo o desenvolvimento de outras culturas adicionais, mesmo aquelas ligadas à sobrevivência humana. A monocultura e o latifúndio compõem os dois fenômenos característicos do Nordeste e marcam a forma como se evoluiu a economia nordestina.

A monocultura de cana-de-açúcar é altamente concentradora de renda, centralizando a riqueza nas mãos de um reduzido número de latifundiários. Como consequência, toda a economia concentradora de renda tende a dificultar a formação de mercado interno. De maneira que essa economia

\footnotetext{
Altamente concentradora de renda, dificultou a formação de um mercado interno, sem o qual não é possível passar da economia de exportação para a economia industrial (FURTADO, 1959, p. 21).
}

A economia açucareira nordestina dependia totalmente da demanda do mercado externo, que não tinha capacidade para absorver toda a mão de obra que se formava na região. $O$ excedente populacional criado se deslocava para as regiões menos férteis com terras predominantemente mais pobres do agreste nordestino, originado a formação de minifúndios. É interessante observar que o crescimento e a expansão da pecuária não se deram como resultado do sucesso do desenvolvimento da cultura pecuarista, e sim como consequência do declínio e debilitamento da produção açucareira. Com o aumento populacional e a estagnação 
demográfica, a migração para interior se tornou mais robusta levando esses excedentes populacionais a áreas de região semiárida, sujeitas a incidência das secas. Assim,

\begin{abstract}
Em linhas gerais, foi este o processo de formação histórica da economia nordestina: quando as exportações do açúcar perderam o impulso de crescimento, esgotou-se toda a força dinâmica do sistema, que se revelou incapaz de propiciar a transição automática para a industrialização. O Nordeste deixou de contar, há muito tempo, com um autêntico fator dinâmico, capaz de substituir o açúcar. Quando o açúcar entrou em estagnação, o Nordeste passou a constituir uma economia totalmente a míngua de impulso de crescimento, embora continuasse expandir-se horizontalmente, pela economia de subsistência e a ocupação de terras de inferior qualidade e mais sujeitas ao fenômeno das secas (FURTADO, 1959, p. 23-24).
\end{abstract}

Furtado quando discute a problemática nordestina, toca sempre num problema comum e persistente da região, que é o fenômeno das secas, que assola o interior semiárido do Nordeste, chamado de sertão - contração de desertão. Essa extensa zona que estende por quase um milhão de $\mathrm{Km}^{2}{ }^{4}$ atingindo os Estados do Ceará, Rio Grande do Norte, Paraíba, Pernambuco, Bahia, Piauí, Sergipe e Alagoas. Essas áreas sofrem com os colapsos periódicos de precipitações pluviométricas. A região de secas se caracteriza pela queda acentuada e irregular de suas precipitações, a estação seca pode durar de sete a oito meses. O clima seco forma uma vegetação típica do sertão nordestino, que é a caatinga, totalmente adaptada à região a caatinga se defende das secas usando de forma parcimoniosa suas reservas de água, no inverno os gravetos secos se transformam em pastagens verdes. $\mathrm{O}$ autor descreve que,

A fazenda típica da região sertaneja combina a pecuária como algodão-mocó, o trabalho assalariado na pecuária com a "meação" na agricultura. Se visitarmos uma fazenda dessas, encontraremos um conjunto de família de "moradores" - porque não são propriamente empregados, não tem salário monetário, são digamos, sócios nos riscos e na venda da produção algodoeira, com direito a casa e a uma faixa de terra para lavoura de subsistência (Ibid, p. 28).

O autor afirma que o fenômeno das secas se agrava pela inadaptação da estrutura econômica predominante da região com as condições naturais preexistentes, que resulta na grande quantidade de pessoas flageladas pela seca. Esse contingente populacional foi resultado de um processo autônomo de ocupação. A seca que ocorre periodicamente na região não afeta gravemente o algodão, atinge um pouco mais o gado, que pode ser deslocado para regiões menos afetadas pelas secas onde as pastagens são melhores. Entretanto, a produção de alimentos é a mais afetada, fazendo com que grande parte dos meeiros fique praticamente sem alimento. Furtado conclui que,

O mínimo que se pode dizer, portanto, é que se criou na região um sistema econômico vulnerável e instável, inadaptado ao meio (FURTADO, 1959, p. 29).

A produção alimentícia era o ponto débil dos três setores produtivos da região, concentrada nas mãos dos trabalhadores rurais, com a finalidade única de autoconsumo. A fome

\footnotetext{
${ }^{4}$ Informação retirada do livro: A Operação Nordeste. Furtado, Celso. 1959, pág.25
} 
dispersava a população para áreas mais atrativas interferindo na disponibilidade de mão de obra na produção de algodão. Foi a calamidade trazida pelas secas, inicialmente pela grande estiagem de 1877-1879, que identificou a seca como um escândalo nacional, personificando-a num problema que necessitava de atenção. Furtado relata que,

\begin{abstract}
A partir de então, a ação do governo federal desenvolveu-se em dois sentidos: aumentar a retenção das águas da superfície, o que favorece a pecuária, e evitar os deslocamentos de gente na ocorrência de seca, fornecendo à população concernida meios de subsistência. Essa a origem das famosas "frentes de trabalho", mais ou menos improvisadas, que tenderam proliferar nos períodos de estiagens severas. Ora, a ação do governo veio reforçar o status quo existente. Com efeito, o quadro de fome criado pela seca não é percebido como decorrente de decisões tomadas pela classe dirigente reflexo de uma estrutura social que estava sendo reforçada pela ação do governo. O crescimento demográfico pode assim prosseguir, criando condições para que as fazendas prosperassem e a classe de senhores de terras aumentasse seu poder (FURTADO, 1989, p. 22).
\end{abstract}

A sociedade nascida da região semiárida se formou ao redor das fazendas. O poder econômico e o político se confundiam, tendo como centro irradiador os senhores de terras. As pequenas vilas eram uma extensão das fazendas, a população sem instrução e expectativas era totalmente subordinada aos proprietários de terras, criando uma situação de dependência e "proteção". A arrecadação dos impostos, a polícia e a justiça eram manipuladas direta ou indiretamente pelos senhores terras em nome do governo estadual. Os mandantes locais intermediavam a ação do governo federal em períodos de seca, se beneficiando dos recursos públicos para construir barreiras, estradas e outras benfeitorias em suas terras. A população camponesa que sobrevivia da economia pecuária, não dispunha de margem para acumular, devido à baixa produtividade do setor. Marcada pelo imobilismo, reproduzia o passado de forma mecânica. A produtividade pecuarista de subsistência tinha a família como unidade de produção, não viabilizando a extração de um excedente significativo, só o necessário para reproduzir-se. Desta forma, o resultado era o imobilismo nas técnicas produtivas.

Ao visitar o semiárido durante a seca de 1958, Furtado descreve que lá encontrou uma população vivendo em condições de penúria, se não fosse a ação do governo, muitas pessoas iriam morrer de fome ou emigrar para outras áreas, reestruturando a economia regional. Todavia, a classe de proprietários de terras não parecia tão afetada como a primeira. Pois,

A ação do Poder Público eliminava essa solução "natural" e permitia que as estruturas tradicionais sobrevivessem. Populações que, para os proprietários de terras, desempenhavam a função de "curral eleitoral" eram retidas com meios artificiais (FURTADO, 1989, p. 39).

Nas regiões urbanas litorâneas não era muito diferente.

Uma cidade de meio milhão de habitantes, como Fortaleza, não dispunha de serviço de água encanada. A água, retirada de poços, era poluída por infiltrações de fossas que substituíram o serviço de esgoto. Não havia instalações portuárias: o embarque e o desembarque de mercadorias de mercadorias eram feitos em precárias alvarengas, com enormes perdas [...] Em todas as partes da região as atividades industriais estavam em 
declínio, incapacitadas para fazer face à concorrência dos produtos provenientes do Centro-Sul a que se começa a ter acesso por via rodoviária (Ibid, p. 39).

No campo político, a disputa era acirrada em busca das verbas disponibilizadas pelo governo federal. Surgia então, uma constante valorização da representação parlamentar e o constante empenho dos congressistas em ocupar lugares importantes no Parlamento Nacional. A política era marcada pelo favoritismo e barreiras que impediam a entrada de pessoas indesejadas no ramo, perpetuando o poder nas mãos de parentes e protegidos. Essa corrupção na política nordestina só agravava a decadência da região, expulsando direta ou indiretamente as pessoas mais capazes e empreendedoras.

Celso Furtado sintetiza os alicerces do subdesenvolvimento, no texto abaixo, como algo de natureza estrutural e complexa:

\begin{abstract}
As sociedades que não realizaram qualquer investimento no fator humano até os albores do século atual foram condenadas às piores formas de subdesenvolvimento. A passividade da população, sua inaptidão para organizar-se na ação política, seu profundo sentimento de insegurança, levando-a a buscar proteção, contribuíram para implantar o imobilismo social e a estagnação econômica. A rígida hierarquia social e o monopólio da informação em mãos de poucos explicam a arrogância e o autoritarismo da classe dirigente. Assim, o ecológico, o social e o político se entrelaçam para produzir o duro cimento em que se alicerçou o subdesenvolvimento do Nordeste (Ibid, p. 23).
\end{abstract}

Dessa forma, interpreta-se a situação do Nordeste brasileiro como resultado de uma série de deficiências sociais, estruturais, políticas e econômicas, que interagem ocasionando um estado de subdesenvolvimento, trazendo, por sua vez, todas as suas mazelas ou características,que se personificam na baixa flexibilidade da ascensão social, na pobreza e na desinformação de grande parte do sofrido povo nordestino brasileiro.

\title{
O PLANEJAMENTO DE FURTADO NA LUTA CONTRA O SUBDESENVOLVIMENTO NORDESTINO
}

Celso Furtado articula a questão regional vinculando-a sempre com a questão nacional, pois uma integra a outra. Usa como base a análise histórica da formação econômica, que em algumas ocasiões, resultaram nas deformações reprodutivas do desenvolvimento, originando $\mathrm{o}$ subdesenvolvimento. Para o autor, o planejamento econômico é a única forma de reverter à condição distorcida do desenvolvimento. Esse seria o grande problema, pois para se planejar e executar um propósito - o longo caminho entre as ideias e a ação - são necessárias grandes batalhas ideológicas, combatendo muitas vezes os pensamentos anacrônicos, conservadores e ineficientes, sedimentados e formadores da instituição nacional. Durante toda a obra furtadiana, fica clara a importância da associação entre o político e o econômico para a superação do subdesenvolvimento, tanto regional, 
quanto nacional. O verdadeiro desenvolvimento é um processo de ativação e canalização das forças sociais, fundamentadas no avanço da iniciativa e da inventividade. Assim, o desenvolvimento é um processo social e cultural, subsidiado pela força econômica. Assim,

\begin{abstract}
Produz-se o desenvolvimento quando na sociedade manifesta-se uma energia capaz de canalizar de forma convergente, forças que estavam latentes ou dispensas [...] Uma verdadeira política de desenvolvimento terá que ser a expressão das preocupações e aspirações de grupos sociais que tomam consciência de seus problemas e se empenham em resolvê-los (FURTADO, 1983a, p.149).
\end{abstract}

Furtado utilizou o conhecimento técnico e empírico adquirido na $\mathrm{Cepal}^{5} \cdot$, com relação às economias desenvolvidas e subdesenvolvidas nacionais, para situar e analisar a condição regional brasileira dentro dessa mesma dimensão. Acreditava-se que a entrada da região Nordeste na onda desenvolvimentista nacional, que estava em voga, seria importante para capacitá-la de desenvolver força suficiente para modificar as tendências do atraso produzido pelo subdesenvolvimento.

Somente a partir de 1879, no fim de uma das maiores secas da história do Nordeste do Brasil, o governo central, representado por Dom Pedro II, passou a encarar com mais atenção à problemática regional nordestina. A primeira iniciativa foi a criação de uma comissão que estudaria uma forma de amenizar a problemática regional. Essa comissão chegou a conclusão, que o problema nordestino se fundamentava pela questão hídrica, ou seja, no fenômeno das secas. Em 1909 no governo de Nilo Peçanha foi criada a Inspetoria de Obras Contra a Seca (IFOCS), vinculada ao Ministério da Aviação e Obras Públicas. No ano de 1945 esse órgão passou a ser chamado de Departamento Nacional de Obras Contra a Seca (DNOCS). As ações desses órgãos se baseavam na construção açudes e barreiras, com o objetivo de atenuar o que se acreditava ser a causa fundamental do problema regional nordestino, sua irregularidade de precipitações e a escassez hídrica.

Muitas vezes o insucesso dessas medidas, que na verdade eram paliativas, resultava da própria estrutura política, econômica e social do Nordeste, pois a predominância de latifúndios e da desigualdade da renda dificultava a eficácia dos projetos. Como dito anteriormente, algumas dessas obras eram feitas em terrenos particulares, beneficiando somente a elite regional.

O Banco do Nordeste do Brasil (BNB) foi criado no Governo Vargas em 1951, após uma grande estiagem. O banco surgiu com a missão de criar um mecanismo que desenvolvesse a atividade econômica na região. Fornecendo crédito a população nordestina na tentativa de promover o aquecimento econômico. É interessante observar que esta foi a primeira medida que visava o planejamento socioeconômico da Região Nordeste fugindo da tradicional assistência as secas.

\footnotetext{
${ }^{5}$ A Comissão Econômica para América Latina é um órgão vinculado as Nações Unidas que tinha a função de promover o desenvolvimento na América do Sul.
} 
No governo de Juscelino Kubitschek (JK), em 1956, foi criado o Grupo de Trabalho para o Desenvolvimento do Nordeste (GTDN). De forma conjuntural, o Brasil neste período passava por um grande surto desenvolvimentista, pois o então presidente criara condições favoráveis para a entrada do capital produtivo industrial, que se internacionalizava devido à grande euforia econômica internacional. JK neste período estava construindo a futura capital do Brasil, atrelado a isso, criou o slogan de crescer "50 anos em 5" que sinalizava o engate do Brasil nessa onda mundial. As medidas desenvolvimentistas impulsionavam a indústria de base, o investimento na produção hidrelétrica e a construção de estradas, reforçando o processo industrializante concentrado na Região Sudeste. Esse novo surto industrial instigava o debate sobre a questão regional, que se fundamentava nas diferenças dos níveis de desenvolvimento das regiões brasileiras, que naquele momento se intensificavam.

De início o grupo não teve muito sucesso, porém em 1958 devido a uma grande seca que atingiu o Nordeste, o presidente Juscelino Kubitschek convidou o então diretor do Banco Nacional de Desenvolvimento Econômico (BNDE), Celso Furtado para dirigi-lo. A partir de então, Furtado passou a integrar a GTDN e fundou em 1959 a Superintendência de Desenvolvimento do Nordeste (SUDENE). Furtado dizia que o que estava sendo feito era muito bom para o Brasil, porém era muito ruim para o Nordeste, o surto desenvolvimentista concentrado na região paulista era importante para o Brasil, entretanto era preciso pensar em outras regiões que concentravam também um grande contingente populacional e que precisavam de políticas desenvolvimentistas. Então, foi apresentada uma tentativa de desenvolver o Nordeste que se encontrava em estado crítico em todos os aspectos, através do documento intitulado: Uma Política de Desenvolvimento Econômico para o Nordeste. De maneira objetiva,

A ideia central era produzir um documento que contivesse uma explicação do subdesenvolvimento do Nordeste visto como a região de um país, o Brasil, subdesenvolvido [...] Em seguida, apresentaria as linhas gerais de uma estratégia de ação, cujo objetivo último era deter a degradação da economia e incorporar a região ao processo de desenvolvimento então em curso no Centro-Sul [...] Era um convite para superar as discussões vagas sobre o "abandono do Nordeste" e para engajar-se com clareza num programa de ação visando a mudar o ruma da História numa região secularmente à deriva(FURTADO, 1989, p. 40).

Furtado ao entrar na GTDN analisou a forma como o pouco recurso disponível estava sendo usado, era revertido em obras de açudagem e missões emergenciais sem planejamento de assistência as vítimas flageladas pela seca. $\mathrm{O}$ autor sabia que muitos estudiosos brasileiros haviam pensado sobre o problema da região Nordeste, mas infelizmente, com estreiteza em seu campo de visão. A teoria exposta por Furtado era diferente das defendidas pelas elites regionalistas, de procedência técnica ela não colocava a seca como a principal causa do flagelo do povo nordestino, a política regional tradicional ineficiente era o cerne do problema. Faltava relacionar as condições naturais com as estruturas socioeconômicas existentes, que de certa 
forma acentuavam os problemas causados pelas secas. Por outro lado, era necessário também, compreender as peculiaridades das relações do Nordeste brasileiro com o emergente polo industrial do antigo Centro-Sul.

Nesse pano de fundo, Furtado em seu projeto econômico desenvolvimentista, partia do ponto da disparidade de níveis de renda existentes entre o Nordeste e o Sudeste do Brasil, pois este formava o mais grave problema no então processo de desenvolvimento nacional.

Em moeda corrente da época, a renda per capta da região era inferior 100 dólares, correspondendo a cerca de $30 \%$ da do habitante do Centro-Sul (FURTADO, 1989, p. 53).

As atenções também eram voltadas para a diferença no ritmo do crescimento da produção e da renda, pois poderia acarretar na divisão do país em dois - uma reprodução da relação centro-periferia- de um lado formado por um polo industrial extremamente dinâmico e por outro uma região fornecedora de mão de obra barata e matérias primas, caracterizada pela baixa produtividade.

Quando se analisava os resultados das relações comerciais do Nordeste com o exterior e o Sudeste, constatava-se que a metade das divisas nordestinas captadas com a exportação eram direcionadas para a região Centro-Sul na forma de compras. As duas regiões formavam um duplo fluxo de recursos. O setor privado drenava recursos para o Centro-Sul, enquanto o setor público operava no sentido inverso. Os recursos públicos recebidos pelo Nordeste vinham quase que exclusivamente direcionados para obras assistenciais, não contribuindo muito para o aumento da capacidade produtiva e de emprego. Pois,

\footnotetext{
O governo Federal, através de transferências de recursos que realiza- ponderávamosinfluencia significativamente o comportamento da economia regional. Estudos feitos sobre um ano determinado (1953) revelaram que $40 \%$ dos dispêndios federais na região foram financiados com transferências, montando estas a cerca de $3 \%$ do produto regional. Fossem estes recursos aplicados em investimentos, a taxa de crescimento seria significativamente mais alta (Ibid, p. 53).
}

A nova política econômica defendia que o essencial era a busca de um novo impulso para o desenvolvimento regional nordestino. O aumento das exportações de produtos primários, muitas vezes, não era suficiente para promover o desenvolvimento. De modo geral, o desenvolvimento se torna exequível quando se diversifica a pauta produtiva interna, através da industrialização. Somado à isso,

Estima-se que $30 \%$ da força de trabalho humana do Nordeste se encontra desempregada, ou subempregada, situação essa que agrava dia a dia. (Ibid, p. 55).

A industrialização tinha a missão tripla de empregar a população ociosa, criar uma classe dirigente comprometida com a causa desenvolvimentista e de manter na região os capitais que tendem a emigrar em buscar de atividades mais produtivas. 
A questão agrária era bastante discutida, pois a grande quantidade de terras localizadas no litoral úmido monopolizadas secularmente pelos latifundiários que as utilizavam para a economia açucareira inibia o surgimento da policultura alimentícia, que de certa forma poderia ser ancilar na manutenção e na criação dos empregos urbanos, usando de forma mais racional os recursos de terras e água dessa sub-região.

A região semiárida não fugia da pauta das soluções para o Nordeste, o complexo da pecuária extensiva e a agricultura de subsistência concentravam um contingente populacional que na maioria das vezes sobrevivia à custa das transferências federais. Do modo que, constituíam culturas pouco monetizadas e frágeis ao fenômeno das secas. A solução era criar uma economia mais resistente às secas, diminuindo a agricultura de subsistência, aumentando em contra partida a produtividade e a renda da classe trabalhadora. A criação da renda impulsionada tanto pelo aumento da produtividade agrícola, quanto pela industrial, reduziria significativamente os efeitos das crises de produção alimentícia, pois a população agora teria poder de compra.

Furtado também propôs os deslocamento das fronteiras agrícolas para a região subamazônica do Maranhão, incorporando novas terras ao Nordeste. Uma vez que atual fronteira agrícola do Nordeste foi estabelecida de forma muito primitiva, como exposto anteriormente, o homem seguiu a boiada, penetrando onde ela podia. A incorporação de terras úmidas ao Nordeste resolveria o problema do abastecimento alimentício, criando uma oferta inelástica de alimentos, podendo até transformar a região em exportadora agrícola, ao mesmo tempo em que monetizaria a economia. Assim, a expansão territorial em direção a terras mais úmidas do Maranhão iria acabar com o desequilíbrio entre os fatores mão de obra e terras. De forma sistemática, chegou-se à

[...] um projeto de plano de ação estruturado em torno de quatro diretrizes básicas: a) intensificação dos investimentos industriais, visando criar no Nordeste um centro autônomo de expansão manufatureira; b) transformação da economia agrícola da faixa úmida, com vistas a proporcionar uma oferta adequada de alimentos nos centros urbanos, viabilizando a industrialização destes; c) transformação progressiva da economia das áreas semiáridas no sentido de elevar sua produtividade e de torná-la mais resistente ao impacto das secas; e d) deslocamento da fronteira agrícola, visando incorporar à economia da região as terras úmidas da hinterlândia maranhense que estão em condições de receber os excedentes populacionais criados pela reorganização da economia na faixa semiárida (FURTADO, 1989, p. 55- 56).

Furtado compôs a SUDENE de 1959 a 1964, data em que ocorreu o golpe militar, quando teve seus direitos políticos cassados. A Ditadura Militar durou 21 anos se estendendo até o ano de 1985. A SUDENE foi extinta no governo FHC no ano 2001 e recriada em 2002, existindo até hoje com sede na cidade do Recife. 


\title{
"A FANTASIA DESFEITA"
}

A proposta feita por Furtado se desviou de seu propósito inicial, na forma e no resultado. O intuito de trazer o Estado desenvolvimentista puramente nacional para o Nordeste não se concretizou. No governo militar a modernização conservadora se instalou e se propagou pelo Brasil e pelo Nordeste. O que aconteceu no Nordeste foi o mesmo processo de modernização mimética ocorrido no resto no Brasil. O padrão de consumo das elites nordestinas se tornou mais sofisticado, reproduzindo o que ocorrera no Sudeste. A modernização se arraigou mais na sofisticação do consumo das elites do que no próprio processo produtivo. O autor desabafa dizendo que

\begin{abstract}
Dedicara anos a organizar minha fantasia, na esperança de um dia transformá-la em instrumento de ação a serviço de meu pobre e desvalido Nordeste. Agora, essa fantasia estava desfeita, desmoronara como uma estrela que se estilhaça. Era como se uma enxurrada tudo houvesse arrastado. (FURTADO, 1989, p. 201)
\end{abstract}

A industrialização avançou progressivamente na região Nordeste. Cidades como, Recife, Fortaleza e Salvador, agora possuíam um parque industrial significativo. Porém essa industrial não era totalmente nordestina, como sonhara Furtado, as políticas governamentais integraram essas áreas a economias maiores, tanto nacionais - tornando-as filiais do Sudeste e do Sul-, como internacionais.

Na Zona da Mata o incentivo do Proálcool ${ }^{6}$ fez a economia açucareira se manter mais presente do que era antes, inibindo a dinâmica de outras economias. Com isso a monocultura continuava presente, cultivada em grandes latifúndios, deixando cada vez mais longe a proposta feita por Furtado de reforma agrária. Além dessa atividade só o turismo litorâneo prevaleceu. No Maranhão, a ocupação das áreas propostas para o deslocamento da fronteira agrícola, na verdade foram ocupadas por sulistas, que usaram as terras férteis para a produção da soja, não para o consumo interno, e sim destinada a exportação.

No semiárido a economia do algodão pereceu, a praga do algodão nos anos de 1980 e 1990 desmontou a economia secular. A produção do algodão foi então deslocada para o Sudeste e o Centro-Oeste. O desaparecimento da economia algodoeira sertaneja afetou a competitividade da pecuária regional eliminando a fonte de renda de grande massa de produtores rurais que viviam dessa cultura. O que amenizou essa situação foi a amparo constitucional da extensão da Previdência aos produtores rurais e de programas assistenciais. Então, não foi o desenvolvimento nacionalista que chegou nessa área, que concentra $40 \%$ da população do Nordeste e sim a manutenção do tradicional assistencialismo governamental.

Com essas informações torna-se visível que as políticas desenvolvimentistas idealizadas por Furtado foram frustradas com o golpe militar de 1964. Incitando a interrupção ou o

\footnotetext{
${ }^{6}$ Programa criado em 14 de novembro de 1975, devido à crise do petróleo na década de 70, substituía a gasolina por álcool etílico, diminuindo a dependência do país do petróleo importando.
} 
adiamento de um sonho de soberania nacional, democracia e homogeneização social na forma de desenvolvimento econômico.

\section{CONCLUSÃO}

Furtado procurou derivar de uma visão mais geral sobre o desenvolvimento e subdesenvolvimento a ideia de subdesenvolvimento regional, privilegiando a região Nordeste. Destarte, ao considerar a formação histórica da região, conseguiu compor um arcabouço teórico capaz de elucidar os determinantes do atraso econômico e social nordestino.

Sendo assim, o autor buscou extrair o conceito de desenvolvimento e subdesenvolvimento, relacionando três dimensões. A primeira dimensão diz respeito à evolução de um sistema social de produção, baseado no contínuo progresso técnico. A segunda dimensão se refere à satisfação, de forma generalizada, das necessidades humanas. A terceira é consecução do que almeja uma classe dominante, relacionando de forma convergente, a produtividade, a homogeneização social e a ideologia da classe dominante.

Desta forma, a busca pela superação do subdesenvolvimento, parte do princípio, de que o subdesenvolvimento é uma má reprodução estrutural das economias desenvolvidas, originada pela forma como se difunde o progresso tecnológico, refletido na dependência cultural e na modernização dos padrões de consumo. Logo, para depreender o desenvolvimento, se faz necessário o esforço de vários agentes, entre eles, o Estado, responsável pela condução das políticas de planejamento, para promover reformas estruturais que levem ao desenvolvimento.

Furtado defende que o "motor" da difusão do desenvolvimento é a industrialização, analisando que no setor secundário se estabelece mais rapidamente o crescimento da produtividade, ocasionado à elevação dos salários e a geração de empregos, denominado como o setor mais dinâmico da economia.

No presente trabalho, o ponto principal foi tentar interpretar a problemática da região Nordeste, que para Furtado é o "espelho onde a imagem do Brasil se reflete com maior nitidez", considerada uma das regiões mais pobres de um país subdesenvolvido.

Em resposta as desigualdades profundas da região Nordeste, o governo de Juscelino Kubitschek, no final da década de 50, criou a Superintendência de Desenvolvimento do Nordeste, a SUDENE. Surgida com a finalidade de contornar o agravamento das disparidades da região Nordeste, retirando do papel a vontade de Furtado de promover a transformação da região mais pobre do País na forma de um plano de ação. Defende a industrialização, a reforma agrária, a adaptação da economia ao clima, como também o deslocamento da fronteira agrícola para terras mais férteis, resolvendo o problema de abastecimento de 
alimentos. Infelizmente, mais tarde, com a ditadura militar de 1964 a força do planejamento furtadiano foi enfraquecida pela sua deportação.

Passados mais de 50 anos da criação da SUDENE, vemos que o processo de industrialização se instalou no Nordeste, porém, não da forma e com o resultado que Furtado esperava, voltado para o mercado interno e promovendo a homogeneização social.

Seguindo a expansão da industrialização do Sudeste, que concentra metade do potencial produtivo do País, a região Nordeste não conseguiu obter mudanças significativas na sua estrutura, tanto econômica, quanto social. Mantendo sua baixa participação no PIB nacional, sua baixa renda per capita e tendo um dos piores indicadores sociais do Brasil. Infelizmente, o Nordeste reproduz na essência imagem perecida daquela esboçada por Furtado há 50 anos. Assim, podemos concluir que a condição precária vivida pelo povo nordestino reflete a pobreza e a falta de qualidade de vida presente nas estruturas subdesenvolvidas. $\mathrm{O}$ "progresso" trazido pela industrialização no Nordeste trouxe mais modernidade do que desenvolvimento, pois a predominância da diversificação produtiva, os benefícios materiais e de bem estar proporcionados pela civilização industrial não se encontram disseminados na região Nordeste.

\section{REFERÊNCIAS BIBLIOGRÁFICAS}

BARCELAR de Araújo, Tânia, ET AL. O pensamento de Celso Furtado e o Nordeste hoje. $1^{\circ}$ Edição. Editora Contra Ponto, 2009.

BIELSCHOWSKY, Ricardo. Cinquenta anos de pensamento na CEPAL. Editora Record. Volume 1. Rio de Janeiro, São Paulo, 2000.

COSTA Lima, Marcos. A atualidade do pensamento de Celso Furtado. Verbena. São Paulo, 2008.

FURTADO, Celso. A Economia Brasileira: contribuição à análise de seu desenvolvimento. Rio de Janeiro, 1954.

A Operação Nordeste. Textos brasileiros de economia. Rio de Janeiro, 1959.

Dialética do Desenvolvimento. Rio de Janeiro, Fundo de Cultura, 1964.

Uma política de desenvolvimento econômico para o Nordeste, 2 ed. SUDENE. Recife, 1967.

O mito do desenvolvimento econômico. Rio de Janeiro: Paz e Terra. 1974.

A Nova Dependência (Dívida externa e Monetarismo). 5 ed. Rio de Janeiro, 1983a.

Teoria e política do desenvolvimento econômico. São Paulo. Nova Cultural, 1983b.

Cultura e Desenvolvimento em época de crise. Paz e Terra, 1984.

A Fantasia Desfeita. 2 ed. Rio de Janeiro: Paz e Terra, 1989.

O subdesenvolvimento revisitado. In: Economia e Sociedade. Campinas, 1992.

Introdução ao Desenvolvimento: enfoque histórico-estrutural. Rio de Janeiro. Paz e Terra, 2000.

Raízes do subdesenvolvimento, Rio de Janeiro. Civilização brasileira, 2003.

Formação Econômica do Brasil. 34 ed. Companhia das letras. São Paulo, 2007.

Desenvolvimento e subdesenvolvimento. Rio de Janeiro. 5 ed. Contraponto, 2009. 
IBGE. Instituto Brasileiro de Geografia e Estatística, Síntese dos Indicadores sociais 2010, 2013, séries históricas e estatísticas. Contas Regionais do Brasil 2011: Disponível em $<$ http://www.ibge.gov.br/home/>

Instituto de Pesquisa Econômica Aplicada, IPEA data/Regional: Disponível em $<$ http://www.ipea.gov.br/portal/>

RIBEIRO, Carine Pereira. Desenvolvimento e subdesenvolvimento segundo Celso Furtado: Influência no debate sobre a questão regional brasileira. 2010. Monografia (Graduação em economia)- Universidade Federal de Santa Catarina, Florianópolis, 2010. 